\title{
Mobile epifauna on Zostera marina, and infauna of its inflorescences
}

\author{
Monika Hellwig-Armonies \\ Biologische Anstalt Helgoland (Litoralstation); D-2282 List/Sylt, FRG
}

\begin{abstract}
The faunal colonization of the leaves and inflorescences of intertidal Zostera marina L. and of the ambient water has been studied at the Island of Sylt (North Sea). The abundance of the snail Littorina littorea L. and the isopod Jaera albifrons Leach correlates significantly with leaf surface area. This is not the case with the abundance of meiofaunal Plathelminthes, Nematoda, Copepoda, and Polychaeta. However, they increase significantly with the numbers of generative shoots in the sampled seagrass bunches. Members of these taxa inhabit the Zostera inflorescences, and average abundance increases with the degree of decay of inflorescences. This temporary microhabitat presumably offers food and shelter. Copepods and ostracods dominate in the ambient water. Planktonic calanoid copepods correlate with the amount of sampled seawater, while Ostracoda correlate with the amount of resuspended detritus suggesting that they were resuspended themselves. The study shows that some meiofaunal taxa can rapidly exploit a short-lived habitat such as the Zostera inflorescences. Juvenile polychaetes use inflorescences as a nursery.
\end{abstract}

\section{INTRODUCTION}

The eelgrass Zostera marina is widespread in temperate zones of the northern hemisphere (den Hartog, 1970). Eelgrass meadows are highly productive and may provide food and shelter for many organisms (den Hartog, 1977). This attracted scientists to perform studies on Zostera communities (partly reviewed by Kikuchi, 1980). Most of these investigations deal with macrofauna, while studies on meiofauna are scarce (see review by Bell et al., 1984) and concentrate on subtropical shallow subtidal habitats. The studied North Sea Zostera bed is located in the intertidal. It bears far less epiphytes than is reported from subtidal habitats (e.g. Nagle, 1968). Many meiofaunal organisms live inside the epiphytic algal felt (Kikuchi, 1980) and a numerical relationship was observed between the abundance of epizoans and epiphytes (Nagle, 1968). Therefore, few meiofaunal dwellers are expected on intertidal Zostera leaves, as was often found in structurally less complex habitats (e.g. Hicks, 1977). However, partly decomposed inflorescences of Zostera marina proved to be a structurally complex microhabitat inhabited by several meiofaunal taxa. Thus meiofauna may use Zostera inflorescences as a nursery as is reported from insects in inflorescences of terrestrial plants (Zwölfer, 1979, 1980; Seifert, 1984). 


\section{MATERIAL AND METHODS}

\section{Study site and sample collection}

Samples were collected from an extensive (about $0.3 \mathrm{~km}^{2}$ ) dense seagrass meadow (mainly Zostera marina) in the intertidal zone near the Island of Sylt, North Sea. Inside the meadow a $10 \times 10 \mathrm{~m}$ plot east of the "Vogelkoje" was selected for sample collection. Tidal emersion of the plot is about $40 \%$ of a tidal cycle; however, some water always remains above the sediment in most parts of the meadow.

Ten eelgrass samples were collected by cutting off bunches of seagrass close to the sediment from a surface area of about $5 \mathrm{~cm}^{2}$. Holding the bunches with one hand at the water surface the bunch was inserted into a plastic bottle with some of the ambient seawater. Ten water samples of 400 to $700 \mathrm{~cm}^{3}$ each were collected above the seagrass. A plastic tube of $10 \mathrm{~cm}^{2}$ cross-sectional area and $0.5 \mathrm{~m}$ length was dipped vertically three times into the water without touching grass or sediment. The enclosed water was transferred to plastic bottles. Both the water and seagrass samples were collected at rising tide (water level 15 to $30 \mathrm{~cm}$, seawater temperature $20^{\circ} \mathrm{C}$, salinity $30 \% \mathrm{~S}$, Aug. 24 , 1987). Water flow and slight wind caused a small amount of material being resuspended from the sediment during sample collection. One of the water samples was later on lost $(n=9)$. The third set of samples consisted of 70 individually collected inflorescences of Zostera marina. These were separately packed in glass jars with filtered seawater (Sept. 18, 1987; during low tide).

The leaves and the inflorescences were transferred into Petri dishes with filtered seawater. Using a stereo microscope, the bunches as well as the single inflorescences were pulled to pieces, and all metazoans removed and counted. The water samples and the residual water of the seagrass samples were filtered through $40 \mu \mathrm{m}$ meshes and the remainder microscopically investigated as before. All samples were intermittently stored at $10^{\circ} \mathrm{C}$ with a natural dark-light rhythm. The maximum period of storage was 7 days.

\section{Determination of leaf surface area}

The width and length of some individual leaves were measured and the measured leaves added to a package until reaching a total leaf length of $1 \mathrm{~m}$. The surface area of such a $1 \mathrm{~m}$-package of leaves was about $40 \mathrm{~cm}^{2}$. It was dried at $100^{\circ} \mathrm{C}$ for $24 \mathrm{~h}$ and weighed. A 3-fold repetition yielded an average dry weight of $40 \mu \mathrm{g} \cdot \mathrm{m}^{-1}$ of leaves, i.e. $1 \mu \mathrm{g} \cdot \mathrm{cm}^{-2}$ of leaf surface area. After sorting the seagrass samples, all leaves of a replicate were collected, washed with fresh water and dried as before. Subsequent weighing and calculation yield the leaf surface area per individual sample. It varied between 160 and $630 \mathrm{~cm}^{2}$.

\section{Classification of inflorescences}

Generative shoots may consist of green, unripe inflorescences as well as completely decayed remainders. Differential numbers of metazoans were found according to the degree of inflorescence degradation. For statistical analyses inflorescences were classified into one of 5 states of decay: (1) Green inflorescences without visible decay (unripe or only female organs ripe); (2) Predominantly green undecomposed material 
(green fruits, a few remainders of pollen sacs); (3) Equal amounts of green and decomposed material (green and decayed fruits, remainders of pollen sacs, empty pericarps); (4) Predominantly decomposed material (a. few unripe fruits, decomposed remainders of pollen sacs and pericarps); (5) Completely decayed (no green parts).

\section{Statistical evaluation}

Untransformed data were used to test for correlations between the abundance of taxa and the sample parameters leaf surface area, number of inflorescences, and amount of water and resuspended material in seawater samples, respectively, following the procedures described in Sachs $(1984$, p. 315). Trends are tested by Spearman's rank correlation coefficient. Independence of ranked data was tested using contingency tables (nullhypothesis: rank of abundance is independent of the decomposition class of inflorescences).

\section{RESULTS}

\section{Fauna of seagrass bunches}

A total of 2064 metazoans was counted from a total leaf surface area of $3420 \mathrm{~cm}^{2}$ (i.e. 604 individuals $1000 \mathrm{~cm}^{-2}$ ). The dominant taxa are Copepoda (Harpacticoidea and Cyclopoidea), Nematoda and Ostracoda (Table 1). The epifaunal snail Littorina littorea and the isopod Jaera albifrons both positively correlate with leaf surface area, and the same tendency is seen in Littorina saxatilis Olivi (Table 1). None of the meiofaunal taxa, however, show such a relationship.

The samples include differential numbers of generative shoots of various degrees of ripeness. The inflorescences are inhabited by Nematoda, Harpacticoida, Plathelminthes and Polychaeta ljuveniles and adults of Polydora ligni Webster and 1 specimen of

Table 1. Metazoan abundance in eelgrass bunches (including blades and inflorescences) related to the leaf surface area (density, individuals $\cdot 1000 \mathrm{~cm}^{-2}$ ) and correlations with leaf area and the number of inflorescences per sample unit (correlation coefficient, significance level). * includes Harpacticoidea and Cyclopoidea; ns: not significant. ' ' Juvenile Mytilus edulis did not occur inside the inflorescences but were attached to the stems of generative shoots

\begin{tabular}{|lccc|}
\hline Taxon & Density & $r$ leaf area & $r$ inflorescences \\
\hline Plathelminthes & 29 & $0.38 \mathrm{~ns}$ & $0.82 \mathrm{p}<0.01$ \\
Nematoda & 150 & $0.40 \mathrm{~ns}$ & $0.93 \mathrm{p}<0.01$ \\
Polychaeta & 10 & $0.27 \mathrm{~ns}$ & $0.96 \mathrm{p}<0.01$ \\
Copepoda* & 191 & $0.51 \mathrm{~ns}$ & $0.72 \mathrm{p}<0.05$ \\
Ostracoda & 122 & $0.36 \mathrm{~ns}$ & $0.32 \mathrm{~ns}$ \\
Hydrobia ulvae & 68 & $0.44 \mathrm{~ns}$ & $-0.28 \mathrm{~ns}$ \\
Littorina saxatilis & 24 & $0.57 \mathrm{p}<0.1$ & $-0.10 \mathrm{~ns}$ \\
Littorina littorea & 2 & $0.69 \mathrm{p}<0.05$ & $0.23 \mathrm{~ns}$ \\
Mytilus edulis L. (juv.) & $*$ & $0.17 \mathrm{~ns}$ & $0.78 \mathrm{p}<0.01$ \\
Jaera albifrons & 7 & $0.70 \mathrm{p}<0.05$ & $0.01 \mathrm{~ns}$ \\
\hline
\end{tabular}


Fabricia sabella (Ehrenberg)]. They prefer the inflorescences to the leaf surface and their abundance correlates significantly with the number of inflorescences per sample unit (Table 1). The abundance of Ostracoda and the mud snail Hydrobia ulvae Pennant correlates neither with leaf surface area nor with the number of generative shoots. The plathelminth fauna (total 98 individuals) is dominated by the proseriat Monocelis fusca Oersted $(\mathrm{n}=69)$. Further species are Promesostoma rostratum Ax $(\mathrm{n}=8)$, Phonorhynchus helgolandicus (Mecznikoff) $(\mathrm{n}=6)$, Macrostomum pusillum $\mathrm{Ax}(\mathrm{n}=6)$, Pseudostomum quadrioculatum Leuckart $(\mathrm{n}=3)$, Ptychopera westbladi (Luther) $(\mathrm{n}=3)$, Ptychopera hartogi $\mathrm{Ax}(\mathrm{n}=2)$ and a juvenile acoel.

\section{Ambient water}

Ambient water (total $5050 \mathrm{~cm}^{3}$ ) contained, on average, 54 metazoans per $1000 \mathrm{~cm}^{3}$ of seawater. Copepoda $\left(25.6 \cdot 1000 \mathrm{~cm}^{-3}\right)$ and Ostracoda $\left(22 \cdot 1000 \mathrm{~cm}^{-3}\right)$ dominate. Plathelminthes and Nematoda occur in low abundance $\left(1.4\right.$ and 0.8 individuals $\cdot 1000 \mathrm{~cm}^{-3}$, respectively). Some of the samples also contain Hydrobia ulvae $\left(4.2 \cdot 1000 \mathrm{~cm}^{-3}\right)$. About a quarter of the copepods are Calanoidea $\left(6.6 \cdot 1000 \mathrm{~cm}^{-3}\right)$. As was expected for this planktonic taxon, the abundance of Calanoida significantly correlates with the amount of sampled water $(p<0.05)$. None of the other taxa shows such a correlation.

The water samples contain different amounts of sediment (mainly fecal pellets of Hydrobia ulvae) resuspended by wave action and, possibly, by disturbance during sample collection. Ostracode numbers correlate significantly with the amount of resuspended sediment (homogeneity of contingency table, $p<0.05$ ), indicating that Ostracoda might be suspended themselves. The same tendency is seen in Hydrobia numbers, although not significant.
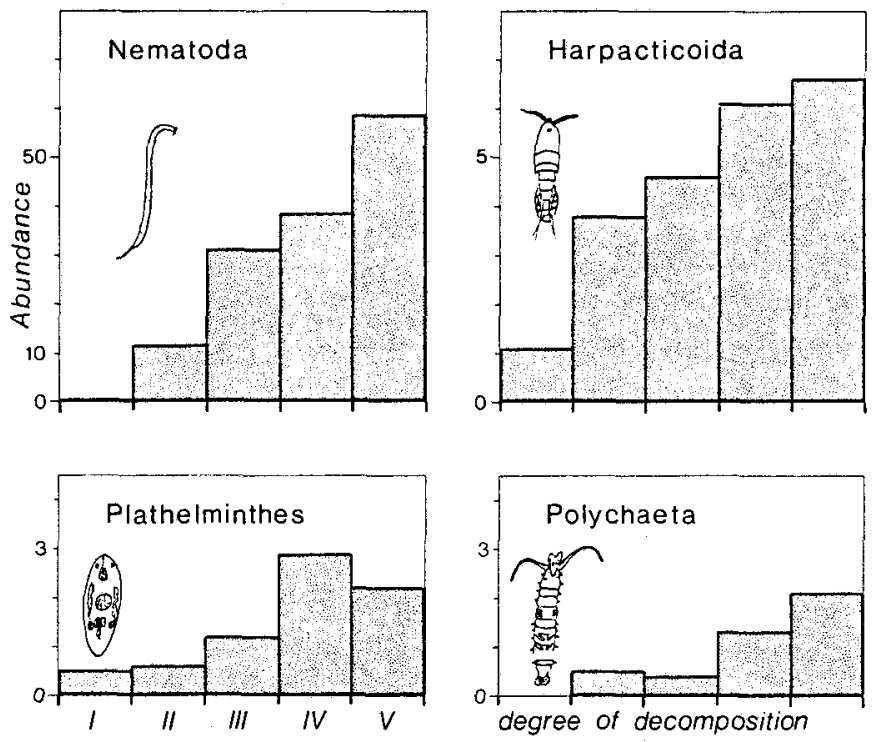

Fig. 1. Abundance (average number of individuals per generative shoot) of taxa in 70 inflorescences of Zostera marina related with the degree of decomposition ( $\mathrm{I}=$ fresh to $\mathrm{V}=$ fully decayed) 


\section{Fauna of individual inflorescences}

The 70 collected generative shoots were classified according to the degree of ripeness and decomposition into 5 groups. Nematoda, Harpacticoida, Plathelminthes and Polychaeta all inhabit these inflorescences. Their abundance inside the inflorescences is analysed using contingency tables (degree of inflorescence decay vs. abundance classes). In none of the above taxa is the table randomly occupied $(p<0.01)$. Instead, highest abundance is always found inside the predominantly decomposed inflorescences (Fig. 1). The correlation is significant for Nematoda and Polychaeta (trend of contingency table, $p<0.01$ and $p<0.02$, respectively). Using Spearman's rank correlation coefficient on the average abundance per degree of decomposition (Fig. 1), all 4 taxa show a significantly positive correlation $(\mathrm{p}<0.01)$.

Nematoda are most abundant inside the inflorescences. An average of 58 and a maximum of 280 individuals was found in fully decomposed inflorescences. However, they do not occupy all parts of the inflorescence equally but usually prefer the decayed pericarp and the remainder of pollen sacs. If these parts are occupied by a high abundance of individuals, then the latter are generally small. Large specimens were found in low numbers only.

Among Copepoda, only harpacticoids occurred inside inflorescences while Cyclopoida were restricted to the outer surface. Some inflorescences contain aggregates of nauplius-larvae (not included in the copepod numbers). During the sorting of the samples, the harpacticoid copepods proved to be highly mobile, often actively leaving the inflorescences before these were opened for investigation. This was not the case in Nematoda and Polychaeta.

The plathelminth assemblage (total 100 individuals) is dominated by Macrostomum pusillum $(\mathrm{n}=65)$ which behaves similarly to harpacticoids in that it leaves the inflorescences every now and then. Phonorhynchus helgolandicus is the next abundant species $(\mathrm{n}=20)$ and was only found inside the inflorescences. Just like Nematoda, it resisted voluntarily leaving the inflorescences during microscopical investigation. Monocelis fusca which dominated the seagrass bunches is relatively scarce in the inflorescences $(n=9)$ where predominantly small specimens occurred. Less abundant is Ptychopera westbladi.

The individual inflorescences sampled in September were inhabited by the polychaetes Polydora ligni $(\mathrm{n}=47)$ and juvenile Arenicola marina $(4-$ to 6 -setiger stage, 18 individuals). They build their tubes inside the inflorescences. No Arenicola occurred in the bunches sampled in August.

Green undecayed inflorescences were in no case inhabited by any of the above taxa. Specimens found together with inflorescences of this kind live on the outer surface (mainly copepods and the plathelminths Macrostomum pusillum and Monocelis fusca). The highest abundance of small benthos is found in fully decomposed inflorescences; however, not every decomposed inflorescence is actually occupied in high abundance. The unoccupied inflorescences might either be already deserted, or might happen to have remained uncolonized. 


\section{DISCUSSION}

\section{Zostera inflorescences as a microhabitat for meiofauna}

The high abundance of Nematoda, harpacticoid Copepoda, Plathelminthes, and Polychaeta found inside Zostera marina inflorescences demonstrates that inflorescences are microhabitats for these taxa. However, since generative shoots are only present during a restricted period of the year and only the more decomposed inflorescences are densely inhabited, it seems unlikely that there might be a highly specialized fauna. An analysis of the plathelminth and polychaete species composition supports this assumption.

Macrostomum pusillum is a diatom feeder living in benthic sandy to muddy sand habitats (Hellwig, 1987). However, the species was not found in the sediment below the Zostera canopy (July and October 1987, unpubl.). Possibly, the Zostera leaves intensively shaded the sediment and thus reduced diatom growth. The same inverse relation of macrophyte vegetation density and abundance of diatom feeders was observed in salt marshes (Armonies, 1986). Phonorhynchus helgolandicus, Monocelis fusca and Pseudostomum quadrioculatum are all thought to be phytal species (Schilke, 1970; Sopott, 1972; Hellwig, 1987). $P$. helgolandicus is unpigmented and was found inside the inflorescences. $M$. fusca and $P$. quadrioculatum are both pigmented and occurred mainly on the surface of inflorescences and blades. Body pigmentation seems to correlate with the swimming behaviour of plathelminths (Armonies, unpubl.).

Ptychopera westbladi ist an abundant nematode-feeder of lentic upper intertidal sediments. High abundance is found in macroalgal mats deposited between Spartina plants (Hellwig, 1987). Ptychopera hartogi occurs in polyhaline Spartina- and supralittoral salt marshes; in the latter area it is mainly found in the macrophyte vegetation cover (Hellwig, 1987; Armonies, 1987). Thus, the plathelminth fauna consists of phytal species and of species living in similar, mostly vegetated habitats.

Polydora ligni is the most abundant polychaete inside the inflorescences. It is known to be rather unspecific in sediment demand (Hempel, 1957; Hauser \& Michaelis, 1975)

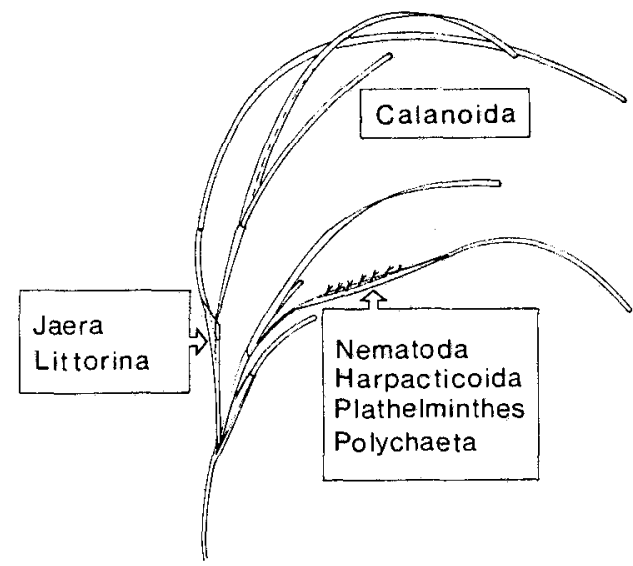

Fig. 2. Taxa showing a significant correlation with (a) the sampled water volume (Calanoida), (b) the Zostera blade surface area (Jaera, Littorina), and (c) the Zostera inflorescences 
and is already known from Zostera marina inflorescences (Michaelis, 1976, 1978). The juveniles of Arenicola marina presumably originate from the burrows of lugworms at the landward side of the Zostera bed. All juveniles were in the 4-to 6-setiger stage and originate from the August spawning (Reise, pers. comm.). Released juveniles migrate downshore and spend their first winter in mud flats at low tide level (Reise, 1985). Obviously, they intermittently rested in the eelgrass bed.

\section{Meio-epifauna on eelgrass leaves}

While Nematoda were most abundant inside the inflorescences, Copepoda dominated the seagrass bunches (consisting of leaves and generative shoots). None of the major meiofaunal taxa correlate with the leaf surface area; however, abundance of Plathelminthes, Nematoda, and Polychaeta is significantly correlated with the number of inflorescences in the bunches (Fig. 2). The correlation is less expressed in Copepoda (Table 1). When subtracting the fauna inhabiting the inflorescences, the remaining leafsurface inhabitants are clearly dominated by copepods.

The information on meiofauna on seagrass leaves is scarce. Copepoda and Nematoda were found to be the dominant taxa on temperate Zostera (Nagle, 1968; Kikuchi, 1980) and Posidonia (Novak, 1982) as well as on subtropical Thalassium (Hopper \& Meyers, 1967; Lewis \& Hollingworth, 1982; Bell et al., 1984). The abundance of meiofauna may vary vertically along Zostera blades and is related to the abundance of epiphytes on the blades (Nagle, 1968; Lewis \& Hollingworth, 1982). Meiofauna can feed on microalgal epiphytes and detritus trapped by larger epiphytes, or get shelter from predation. Nagle (1968) found a direct numerical relationship between epizoic abundance and epiphyte density on Zostera blades. Lewis \& Hollingworth (1982) observed an increasing density of Nematoda, Harpacticoidea, and Polychaeta with increasing encrustation of calcareous epiphytes on Thalassium leaves. The investigated intertidal Zostera leaves were only sparsely overgrown with diatoms, and no detritus occurred on the blades. This may be the cause for the preference of most meiofaunal taxa for decomposed inflorescences compared to blades.

\section{Meiofauna moving between microhabitats}

The water samples contained benthic as well as planktonic species (calanoid copepods). Ostracode abundance correlates significantly with the amount of resuspended detritus indicating passive resuspension. Other taxa such as harpacticoid Copepoda and Plathelminthes are known to swim actively into the water column (e.g. Bell et al., 1984; Hicks, 1986; Walters \& Bell, 1986; Armonies, 1988). Both active emergence and passive drift connect the sediment, seagrass blades, and the water column, which are therefore no distinct habitats for many species. Active emergence from the sediment depends on the light regime and hydrodynamical factors, causing shortterm changes of abundance and faunal composition of each of the 3 compartments (Hicks, 1986; Walters \& Bell, 1986).

The Zostera inflorescences form an additional microhabitat that is numerically dominated by Nematoda (Figs 1 and 2) followed by harpacticoids. The same relation of abundances is found in the sediment below the Zostera canopy (Hellwig-Armonies, 
unpubl.). Cyclopoid Copepoda are only found on the Zostera leaves and on the outer surface of generative shoots. Presumably, the higher faunal similarity of the sediment and partly decomposed inflorescences, in.contrast to that of the leaf surface and the water column, results from (1) structural similarity - an interstitial system is only found in the sediment and the inflorescences; (2) both microhabitats are rather rich in detritus and (3) provide more shelter (from e.g. predation, currents, desiccation) than do the blades. The high abundance of small (presumably juvenile) Nematoda, nauplius larvae, juvenile Polychaeta, and egg-capsules indicates that the Zostera inflorescences may serve as a nursery.

Acknowledgements. This study was supported by a grant of the Biologische Anstalt Helgoland. $\mathrm{K}$. Reise and W. Armonies improved the manuscript by critical comments.

\section{LITERATURE CITED}

Armonies, W., 1986. Free-living Plathelminthes in sheep-grazed and ungrazed supralittoral salt marshes of the North Sea: abundance, biomass, and their significance in food chains. - Neth. $J$. Sea Res. 20, 385-395.

Armonies, W., 1987. Freilebende Plathelminthen in supralitoralen Salzwiesen der Nordsee: Ökologie einer borealen Brackwasser-Lebensgemeinschaft. - Microfauna mar. 3, 81-156.

Armonies, W., 1988. Active emergence of meiofauna from intertidal sediment. - Mar. Ecol. Prog. Ser. $43,151-159$.

Bell, S. S., Walters, K. \& Kern, J. C., 1984. Meiofauna from seagrass habitats: a review and prospectus for future research. - Estuaries 7, 331-338.

Hartog, C. den, 1970. The seagrasses of the world. North-Holland, Amsterdam, 275 pp.

Hartog, C. den, 1977. Structure, function, and classification in seagrass communities. In: Seagrass ecosystems, a scientific perspective. Ed. by C. P. McRoy' \& C. Helfferich. Dekker, New York, 89-121.

Hauser, B. \& Michaelis, H., 1975. Die Makrofauna der Watten, Strände, Riffe und Wracks um den Hohen Knechtsand in der Wesermündung. - Jber. ForschSt. Norderney 26, 85-119.

Hellwig, M., 1987. Ökologie freilebender Plathelminthen im Grenzraum Watt-Salzwiese lenitischer Gezeitenküsten. - Microfauna mar. 3, 157-248.

Hempel, C., 1957. Zur Ökologie einiger Spioniden (Polychaeta sedentaria) der deutschen Küsten. Kieler Meeresforsch. 13, 275-288.

Hicks, G. R. F., 1977. Species composition and zoogeography of marine phytal harpacticoid copepods from Cook Strait, and their contribution to total phytal meiofauna. - J. mar. Freshw. Res. N.Z. 11, 441-469.

Hicks, G. R. F., 1986. Distribution and behaviour of meiofaunal copepods inside and outside seagrass beds. - Mar. Ecol. Prog. Ser. 31, 159-170.

Hopper, B. E. \& Meyers, S. P., 1967. Folicolous marine nematodes on turtle grass Thalassia testudinum König, in Biscayne Bay, Florida. - Bull. mar. Sci. 17, 471-517.

Kikuchi, T., 1980. Faunal relationships in temperate seagrass beds. In: Handbook of seagrass biology: an ecosystem perspective. Ed. by R. C. Phillips \& C. P. McRoy. Garland STPM, New York, 153-172.

Lewis, J. B. \& Hollingworth, C. E., 1982. Leaf epifauna of the seagrass Thalassia testudinum. - Mar. Biol. 71, 41-49.

Michaelis, H., 1976. Die Makrofauna des nördlichen Eversandes (Wesermündung). - Jber. ForschSt. Norderney 27, 167-179.

Michaelis, H., 1978. Zur Morphologie und Ökologie von Polydora ciliata und P. ligni (Polychaeta, Spionidae). - Helgoländer wiss. Meeresunters. 31, 102-116.

Nagle, J. S., 1968. Distribution of the epibiota of macroepibenthic plants. - Contr. mar. Sci. 13, 105-144. 